\title{
Astragaloside IV attenuates hypoxia-induced pulmonary vascular remodeling via the Notch signaling pathway
}

\author{
JIAMEI YAO ${ }^{1-3}$, XIA FANG $^{1,2}$, CUI ZHANG ${ }^{1,2}$, YUSHU YANG $^{1,2}$, DONGSHENG WANG $^{4}$, \\ QIONG $\mathrm{CHEN}^{1-3}$ and GUANGWEI ZHONG ${ }^{1-4}$ \\ Departments of ${ }^{1}$ International Medical Center and ${ }^{2}$ Geriatrics, ${ }^{3}$ National Clinical Research Center for Geriatric Disorders, \\ ${ }^{4}$ Department of Integrated Traditional Chinese and Western Medicine, Xiangya Hospital, \\ Central South University, Changsha, Hunan 410008, P.R. China
}

Received May 23, 2020; Accepted October 27, 2020

DOI: $10.3892 / \mathrm{mmr} .2020 .11726$

\begin{abstract}
The Notch signaling pathway participates in pulmonary artery smooth muscle cell (PASMC) proliferation and apoptosis. Astragaloside IV (AS-IV) is an effective antiproliferative treatment for vascular diseases. The present study aimed to investigate the protective effects and mechanisms underlying AS-IV on hypoxia-induced PASMC proliferation and pulmonary vascular remodeling in pulmonary arterial hypertension (PAH) model rats. Rats were divided into the following four groups: i) normoxia; ii) hypoxia $\left(10 \% \mathrm{O}_{2}\right)$; iii) treatment, hypoxia + intragastrical administration of AS-IV $(2 \mathrm{mg} / \mathrm{kg})$ daily for 28 days; and iv) DAPT, hypoxia + AS-IV treatment + subcutaneous administration of DAPT $(10 \mathrm{mg} / \mathrm{kg})$ three times daily. The effects of AS-IV treatment on the development of hypoxia-induced PAH, right ventricle (RV) hypertrophy and pulmonary vascular remodeling were examined. Furthermore, PASMCs were treated with $20 \mu \mathrm{mol} / \mathrm{l}$ AS-IV under hypoxic conditions for $48 \mathrm{~h}$. To determine the effect of Notch signaling in vascular remodeling and the potential mechanisms underlying AS-IV treatment, $5 \mathrm{mmol} / 1 \gamma$-secretase inhibitor [N-[N-(3,5-difluorophenacetyl)-L-alanyl]-S-phenylglycine t-butyl ester (DAPT)] was used. Cell viability and apoptosis were determined by performing the MTT assay and flow cytometry, respectively. Immunohistochemistry was conducted to detect the expression of proliferating cell nuclear antigen (PCNA). Moreover, the mRNA and protein expression levels of Notch-3, Jagged-1, hes family bHLH transcription factor 5 (Hes-5) and PCNA were measured via reverse transcription-quantitative PCR and western blotting, respectively. Compared with the normoxic group,
\end{abstract}

Correspondence to: Dr Guangwei Zhong, Department of International Medical Center, Xiangya Hospital, Central South University, 87 Xiangya Road, Changsha, Hunan 410008, P.R. China E-mail:zgw7512@sina.com

Key words: Astragaloside IV, hypoxia, pulmonary vascular remodeling, Notch signaling pathway, proliferation hypoxia-induced PAH model rats displayed characteristics of PAH and RV hypertrophy, whereas AS-IV treatment alleviated PAH and prevented RV hypertrophy. AS-IV also inhibited hypoxia-induced pulmonary vascular remodeling, as indicated by reduced wall thickness and increased lumen diameter of pulmonary arterioles, and decreased muscularization of distal pulmonary vasculature in hypoxia-induced PAH model rats. Compared with normoxia, hypoxia promoted PASMC proliferation in vitro, whereas AS-IV treatment inhibited hypoxia-induced PASMC proliferation by downregulating PCNA expression in vitro and in vivo. In hypoxia-treated PAH model rats and cultured PASMCs, AS-IV treatment reduced the expression levels of Jagged-1, Notch-3 and Hes-5. Furthermore, Notch signaling inhibition via DAPT significantly inhibited the pulmonary vascular remodeling effect of AS-IV in vitro and in vivo. Collectively, the results indicated that AS-IV effectively reversed hypoxia-induced pulmonary vascular remodeling and PASMC proliferation via the Notch signaling pathway. Therefore, the present study provided novel insights into the mechanism underlying the use of AS-IV for treatment of vascular diseases, such as PAH.

\section{Introduction}

Pulmonary artery hypertension (PAH) is a major complication associated with chronic obstructive pulmonary disease (COPD), which is one of the most common health problems worldwide $(1,2)$. PAH is frequently observed in patients with advanced COPD and is considered as a predictor of poor outcomes (3). PAH in COPD is caused by the remodeling of pulmonary arteries, which is characterized by the intimal proliferation of poorly differentiated smooth muscle cells and the deposition of elastic and collagen fibers (4). To date, long-term oxygen therapy is the most effective treatment strategy for patients with COPD complicated by $\mathrm{PAH}$ and hypoxia as it can slow or reverse the progression of the disease (5). Conventional vasodilators are not used because of the potential harmful influences of gas exchange, due to inhibition of hypoxic pulmonary vasoconstriction and their lack of efficacy after long-term treatment (6). Therefore, the development of novel drugs and therapeutic strategies for PAH is important. 
In China, patients with COPD and PAH often turn to alternative and complementary treatments, which have been reported to be effective and safe (7). In the Chinese Pharmacopeia, Astragaloside IV (AS-IV; $3-O-\beta$-D-xylopy ranosyl-6-O- $\beta$-D-glucopyranosyl cycloastragenol; Fig. 1) is the major biologically active compound in Huangqi (Radix Astragali Mongolici), a Chinese herbal remedy widely used for the clinical treatment of vascular diseases, such as essential hypertension and PAH $(8,9)$. Recently, a study in vitro experiments have confirmed that AS-IV can stimulate human umbilical vein endothelial cell proliferation and the development of tube-like structures (10). Furthermore, AS-IV can suppress platelet-derived growth factor-BB-induced vascular smooth muscle cell proliferation and migration, potentially via inhibition of the p38MAPK signaling pathway $(11,12)$. The results indicated that AS-IV may serve an important therapeutic role in diseases caused by abnormal vascular function.

The pathogenesis of PAH is relatively complex and is not completely understood (13). Pulmonary vascular remodeling is an important marker of the degree of severity and progression in $\mathrm{PAH}$, which is primarily due to the imbalance between pulmonary artery smooth muscle cell (PASMC) proliferation and apoptosis $(14,15)$. Notch signaling, a highly evolutionarily conserved signaling pathway, serves an important role in regulating cell fate proliferation, differentiation and apoptosis $(16,17)$. Notch-3 targets hes family bHLH transcription factor 5 (Hes-5), which is expressed exclusively in smooth muscle cells (SMCs) in adults and might be associated with SMC identity, maturation and proliferation $(18,19)$. In vitro, PASMCs from patients with PAH display higher mRNA and protein expression levels of Notch-3 and Hes-5 compared with healthy controls (20). Moreover, Notch-3 knockout mice display a lack of PASMCs; however, treatment with the $\gamma$-secretase inhibitor, $\mathrm{N}$-[N-(3,5-difluorophenacetyl)L-alanyl]-S-phenylglycinet-butyl ester (DAPT), which blocks Notch receptor cleavage, attenuates hypoxia-induced $\mathrm{PAH}$ in mice (21). The aforementioned studies indicated that Notch signaling is associated with the development of $\mathrm{PAH}$, favoring a vascular proliferative phenotype. In the present study, hypoxia-induced PAH was established in vitro and in vivo to investigate the regulatory activity of AS-IV in pulmonary vascular remodeling and to explore the underlying mechanisms.

\section{Materials and methods}

Reagents and antibodies. High purity AS-IV (95.8\% by high-performance liquid chromatography; analytical grade) was obtained from the National Institutes for Food and Drug Control. AS-IV was dissolved in DMSO and the final DMSO concentration did not exceed $0.1 \%$. DAPT and MTT were purchased from Sigma-Aldrich (Merck KGaA). TRIzol ${ }^{\circledR}$ Reagent, Super-Script II reverse transcriptase and Hot Master Taq DNA Polymerase were obtained from Takara Bio, Inc. The SYBR-Green I assay kit was from Roche Diagnostics.

Animal model and treatment groups. A total of 40 male Sprague-Dawley rats were obtained from the Center for Experimental Animals, Central South University (license no. 20-010). Male, 12-week-old Sprague-Dawley rats

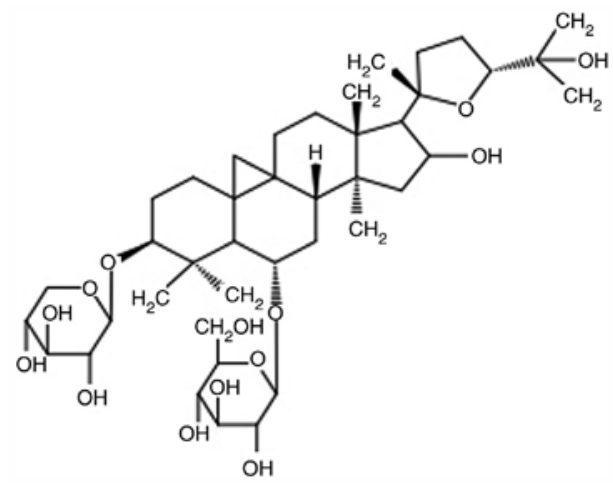

Figure 1. Chemical structure of Astragaloside IV (3-O- $\beta$-D-xylopyranosyl6-O- $\beta$-D-glucopyranosyl cycloastragenol).

(weight, 210 $\pm 10 \mathrm{~g}$ ) were fed a standard diet and water. The temperature and humidity were set at $21-23^{\circ} \mathrm{C}$ and $40-60 \%$, respectively. A 12-h light/dark cycle was used. All animals were acclimatized in the metabolic cages for a week prior to experiments. All animal experiments were approved by the Animal Care and Use Committee of Central South University. The rats were randomly assigned to the following four groups ( $\mathrm{n}=10$ per group): i) normoxia $(\mathrm{N})$; ii) hypoxia $(\mathrm{H})$; iii) treatment (T); and iv) DAPT (DAPT).

Rats in the $\mathrm{N}$ group were exposed to fractional inspired oxygen at $21 \%$. Rats in the $\mathrm{H}, \mathrm{T}$ and DAPT groups were maintained in a Poor Oxygen Controller chamber $\left(10 \% \mathrm{O}_{2}\right.$ for $8 \mathrm{~h} /$ day) for 6 weeks. Anhydrous calcium chloride was used to maintain $<60 \%$ humidity (20). Sodium hydroxide was applied for carbon dioxide absorption.

At the beginning of the third week of hypoxia, rats in the $\mathrm{T}$ and DAPT groups were administered $2 \mathrm{mg} / \mathrm{kg}$ AS-IV intragastrically once daily for 42 days. At the beginning, the second, and the fourth week after hypoxia, rats in the DAPT group were subcutaneously injected with $10 \mathrm{mg} / \mathrm{kg}$ DAPT three times daily.

Measurement of pulmonary arterial pressure. After six weeks of hypoxic exposure, rats were weighed and anesthetized with an intraperitoneal injection of $40 \mathrm{mg} / \mathrm{kg}$ sodium pentobarbital. A micro-catheter (inner diameter, $0.9 \mathrm{~mm}$ ) was gradually inserted via the right external jugular vein into the pulmonary artery. Following a 30 min equilibration period, mean pulmonary arterial blood pressure (mPAP) was collected and analyzed using a BL-420F biological and functional information collection system (Biolap 420F; Chengdu TaiMeng Technology Co.). The right lung was frozen in liquid nitrogen, fixed with $10 \%$ formalin for $48 \mathrm{~h}$ and subsequently used for histology and IHC analyses. RV hypertrophy was assessed in the right and left ventricles, and the septum weight ratio was calculated according to the following formula: (RV weight/LV weight $+S$ weight), where $S$ is the septum.

Histology and microscopy. Formalin-fixed lung tissue was embedded in paraffin and cut into 5- $\mu \mathrm{m}$ thick sections. Subsequently, tissue sections were stained with hematoxylin and eosin (H\&E) as previously described (22). Stained sections were observed in four randomly selected fields of view using an SZX7 light microscope (magnification, x200; 
Olympus Corporation) and analyzed using Image-Pro Plus software 6.0 (Media Cybernetics, Inc.). The results were evaluated according to elastic fiber staining, which is indicated by black or dark blue staining. The distance between inner and outer elastic fibers was calculated in each field of view and the average of three measurements was calculated to determine the thickness of vessel walls.

Immunohistochemistry. For immunohistochemistry, lung sections (5- $\mu \mathrm{m}$ thick) were deparaffinized in xylene, rehydrated using a graduated alcohol concentration series, then washed with PBS ( $\mathrm{pH}$ 7.2-7.4). Following antigen retrieval at $100^{\circ} \mathrm{C}$ and blocking with $5 \% \mathrm{BSA}$ at room temperature for $1 \mathrm{~h}$, the sections were incubated overnight at $4^{\circ} \mathrm{C}$ with a rabbit anti-PCNA antibody (1:200, cat. no. 13110; Cell Signaling Technology, Inc.) and parallel control samples were treated with PBS. Subsequently, sections were incubated with HRP-conjugated anti-rabbit IgG secondary antibody (1:200, cat. no. 31460; Invitrogen; Thermo Fisher Scientific, Inc.) for $2 \mathrm{~h}$ at room temperature. Sections were visualized using DAB and counterstained using hematoxylin. Positive staining was indicated by brown and yellow. The positive staining area in pulmonary vessels were observed under a light microscope (magnification, x400; Nikon Corporation). The integrated optical density (IOD) of PCNA in the pulmonary arteriole was examined using Image-Pro Plus 4.5 software (Media Cybernetics, Inc.), and the ratio of the IOD to the area of the arteriole was calculated to assess the expression of PCNA. The number of PCNA-positive pulmonary vessels was considered as an index of cell proliferation.

Cell culture. PASMCs were isolated from the pulmonary arteries of each rat, as previously described (23). Briefly, the endothelia were removed from isolated pulmonary arteries using a sterile cotton swab, gently digested with $0.2 \%$ collagenase and incubated with PBS supplemented with $0.1 \%$ BSA (cat. no. P3688, Sigma-Aldrich; Merck KGaA) at $37^{\circ} \mathrm{C}$ for $2 \mathrm{~h}$. Digested PASMCs were incubated in DMEM (cat. no. D6046; Sigma-Aldrich; Merck KGaA) supplemented with 20\% FBS (cat. no. 12003 , Sigma-Aldrich, Merck) at $37^{\circ} \mathrm{C}$ with $5 \% \mathrm{CO}_{2}$ for 5-7 days. Primary cell cultures at passage 3-5 were used for subsequent experiments. To determine cell purity, PASMCs were subjected to $\alpha$-smooth muscle actin ( $\alpha$-SMA) immunofluorescence staining.

$\alpha$-SMA immunofluorescence. PASMCs were fixed in $4 \%$ formaldehyde for $15 \mathrm{~min}$ at $25^{\circ} \mathrm{C}$, then incubated in $12 \%$ normal goat serum (Vector Laboratories, Inc.) for $30 \mathrm{~min}$ at $25^{\circ} \mathrm{C}$. The cells were then incubated with the primary rabbit anti- $\alpha$-smooth muscle actin antibody (cat. no. 19245S; 1:200; Cell Signaling Technology, Inc.) overnight at $4^{\circ} \mathrm{C}$. Next, cells were incubated with an goat anti-rabbit IgG secondary antibody (cat. no. 31460; 1:200; Invitrogen; Thermo Fisher Scientific, Inc.) for $2 \mathrm{~h}$ at $37^{\circ} \mathrm{C}$. Propidium iodide $(2.0 \mu \mathrm{mol} / \mathrm{l}$; cat. no. $4087 \mathrm{~S}$; Cell Signaling Technology, Inc.) was used to stain the cell nuclei for $1 \mathrm{~h}$ at $37^{\circ} \mathrm{C}$. The images were observed using a DMI3000B fluorescence microscope (Leica).

Cells were exposed to normoxia $\left(21 \% \mathrm{O}_{2}\right.$ and $\left.5 \% \mathrm{CO}_{2}\right)$ or hypoxia $\left(3 \% \mathrm{O}_{2}\right.$ and $5 \% \mathrm{CO}_{2}$ balanced with $\left.92 \% \mathrm{~N}_{2}\right)$ for
$6,12,24$ or $48 \mathrm{~h}$. PASMCs were divided into the following four groups: i) $\mathrm{N}$; ii) $\mathrm{H}$; iii) $\mathrm{T}$; and iv) DAPT. PASMCs in the $\mathrm{N}$ group were cultured in normoxic conditions for $48 \mathrm{~h}$ and PASMCs in the $\mathrm{H}$ group were cultured in hypoxic conditions for $48 \mathrm{~h}$. PASMCs in the T group were cultured in serum-free medium supplemented with 5, 10 or $20 \mu \mathrm{mol} / \mathrm{l} \mathrm{AS-IV} \mathrm{for} 48 \mathrm{~h}$ under hypoxic conditions. Cells in the DAPT group were pretreated with $5 \mathrm{mmol} / \mathrm{l}$ DAPT, the Notch signaling pathway inhibitor, for $1 \mathrm{~h}$, then cultured in medium supplemented with $20 \mu \mathrm{mol} / \mathrm{l} \mathrm{AS}-\mathrm{IV}$ under hypoxic conditions for $48 \mathrm{~h}$.

Cell viability assay. PASMCs were subjected to cell cycle arrest for $24 \mathrm{~h}$. Subsequently, cells were transferred to PBS containing 5\% FBS for $48 \mathrm{~h}$ at room temperature under normoxic or hypoxic conditions. Cells were pretreated with DAPT for $1 \mathrm{~h}$, then treated with AS-IV under hypoxic conditions at $37^{\circ} \mathrm{C}$ for $48 \mathrm{~h}$. Subsequently, PASMCs were cultured in medium containing $0.5 \% \mathrm{MTT}$ for $4 \mathrm{~h}$ at $25^{\circ} \mathrm{C}$. DMSO was used to dissolve the purple formazan for $10 \mathrm{~min}$ at $37^{\circ} \mathrm{C}$. The absorbance was measured at a wavelength of $540 \mathrm{~nm}$ using a spectrophotometer.

Flow cytometry. Pulmonary vascular remodeling in rats is characterized by increased vascular smooth muscle and endothelial cell proliferation (24). To assess cell cycle distribution, cells $\left(5 \times 10^{5}\right)$ were seeded into glass dishes, digested by trypsinization and fixed with $75 \%$ ethanol. Before cell cycle analysis, the ethanol-fixed cells were centrifuged at $1,000 \mathrm{xg}$ for $10 \mathrm{~min}$ and washed three times by resuspending the cells in PBS at room temperature. The cells were stained with $500 \mu 1$ FxCycle $^{\mathrm{TM}}$ propidium iodide (PI)/RNase staining solution (Thermo Fisher Scientific, Inc.) at room temperature in the dark for $30 \mathrm{~min}$. The stained samples were then transferred to new sterile flow cytometry tubes and maintained on ice until the samples were analysed by flow cytometry using a BD FACSCanto ${ }^{\mathrm{TM}}$ II flow cytometer (BD Biosciences), and cell cycle distribution was determined using ModFit LT software 3.1(Verity Software House). The cell proliferation index was calculated according to the following formula: Proliferation index $(\%)=\left(\mathrm{S}+\mathrm{G}_{2} / \mathrm{M}\right) /\left(\mathrm{G}_{0} / \mathrm{G}_{1}+\mathrm{S}+\mathrm{G}_{2} / \mathrm{M}\right) \times 100$.

Reverse transcription-quantitative PCR (RT-qPCR). Total RNA was isolated from rat distal pulmonary vessels and PASMCs using a TRIzol ${ }^{\mathrm{TM}}$ reagent (cat. no. 15596018; Invitrogen; Thermo Fisher Scientific, Inc.) following the manufacturer's protocol. RNA purity was measured as the A260/A280 ratio using a Multiskan Sky Microplate spectrophotometer (cat. no. 51119570; Invitrogen; Thermo Fisher Scientific, Inc.). Total RNA (1,000 ng) was reverse transcribed into cDNA using the RevertAid First Strand cDNA Synthesis kit (Thermo Fisher Scientific, Inc.). Reverse transcription was performed using the following temperature protocol: $37^{\circ} \mathrm{C}$ for $1 \mathrm{~h}$ and $94^{\circ} \mathrm{C}$ for $5 \mathrm{~min}$. All primers used were designed using the Primer Express ${ }^{\mathrm{TM}}$ software v.3.0.1 (Thermo Fisher Scientific, Inc.) and are listed in Table SI. The reverse-transcribed cDNA was then subjected to PCR using Taq DNA polymerase (cat. no. 10342020; Invitrogen; Thermo Fisher Scientific, Inc.). Subsequently, qPCR was performed using the SYBR-GreenER PCR kit. The following thermocycling conditions were used for $\mathrm{qPCR}$ : Initial denaturation at $94^{\circ} \mathrm{C}$ 

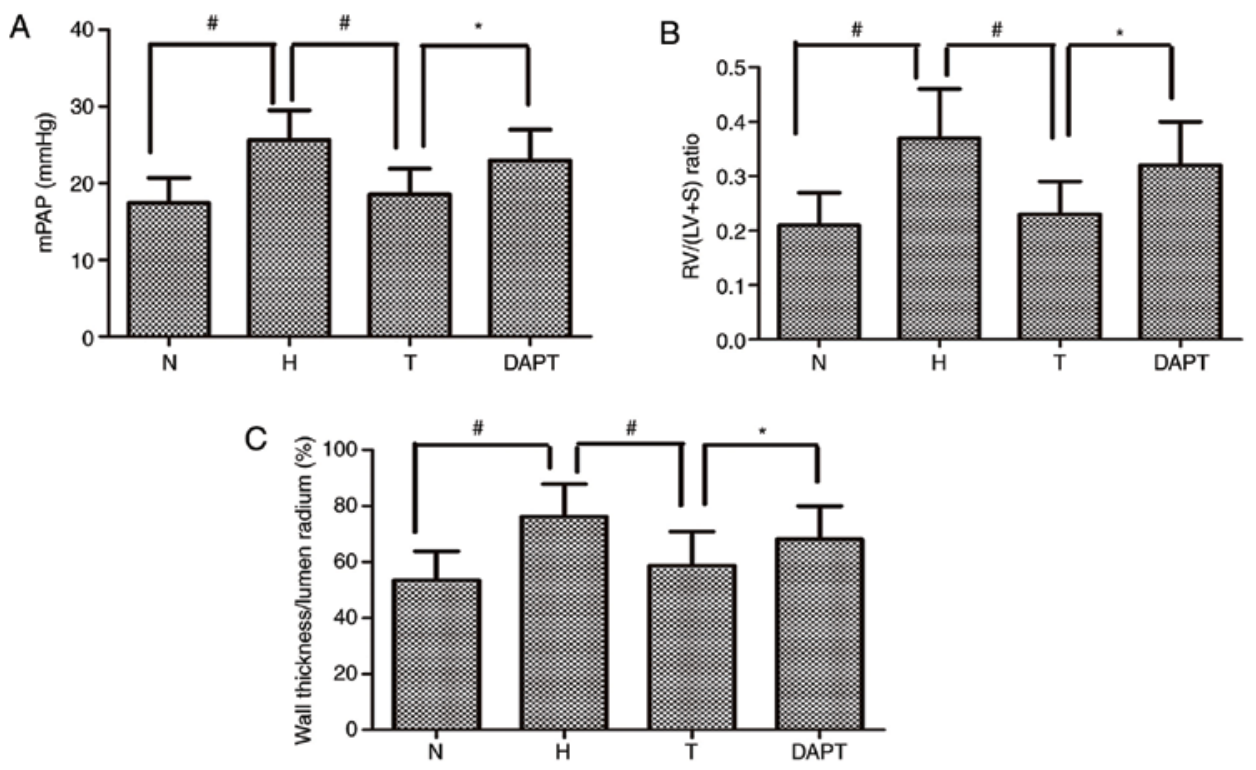

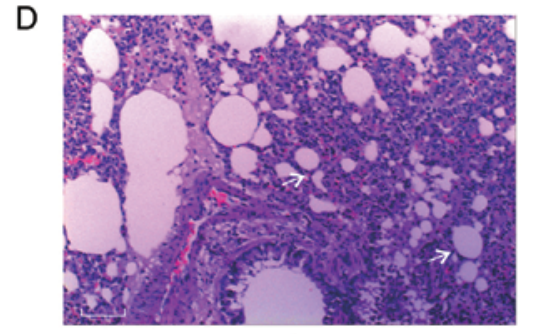

$\mathrm{N}$

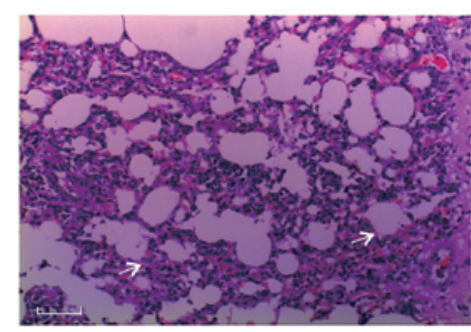

$\mathrm{T}$

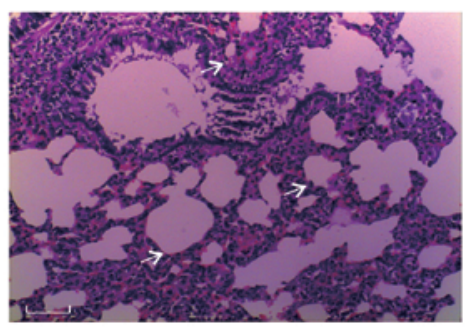

$\mathrm{H}$

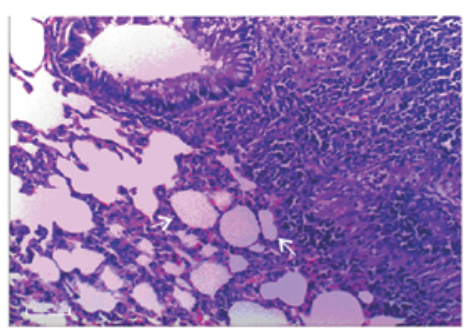

DAPT

Figure 2. Astragaloside IV attenuates chronic hypoxia-induced pulmonary hypertension and pulmonary vascular remodeling. Alterations in (A) mPAP,(B) the $\mathrm{RV} / \mathrm{LV}+\mathrm{S}$ ratio and $(\mathrm{C})$ percentage wall thickness. (D) Hematoxylin and eosin staining of pulmonary arterioles. The white arrow refers to the wall and lumen of pulmonary vessels. Scale bar, $5 \mu \mathrm{l}$. Magnification, $\mathrm{x} 200$. ${ }^{*} \mathrm{P}<0.05$; ${ }^{\#} \mathrm{P}<0.01$. mPAP, mean pulmonary arterial blood pressure; RV/LV+S, right ventricle/left ventricle + septum; N, normoxia; H, hypoxia; T, treatment; DAPT, N-[N-(3,5-difluorophenacetyl)-L-alanyl]-S-phenylglycinet-butyl ester.

for $20 \mathrm{sec}$; followed by 45 cycles of $60^{\circ} \mathrm{C}$ for $30 \mathrm{sec}$ and $72^{\circ} \mathrm{C}$ for $60 \mathrm{sec}$; and a cooling step at $4^{\circ} \mathrm{C}$. mRNA expression levels were quantified using the $2^{-\Delta \Delta \mathrm{Cq}}$ method (25) and normalized to the internal reference gene GAPDH.

Western blotting. Western blotting was performed as previously described (26). Briefly, total proteins were extracted from PASMCs and homogenized lung tissue samples using a lysis buffer containing protease (Beyotime Institute of Biotechnology) and phosphatase inhibitors (Cell Signaling Technology, Inc.). Protein concentrations were measured using the BCA method. Proteins $(50 \mu \mathrm{g})$ were separated via $10 \%$ SDS-PAGE and electrophoretically transferred to equilibrated PVDF membranes using semi-dry transfer. Following blocking with $5 \%$ skimmed milk for $3 \mathrm{~h}$ at room temperature, the membranes were incubated overnight at $4^{\circ} \mathrm{C}$ with primary antibodies targeted against: GAPDH, Notch-3, Jagged-1,
Hes-5 and PCNA (Table SII). Subsequently, the membranes were incubated with anti-rabbit IgG HRP-conjugated antibody (1:200, cat. no. 31470; Invitrogen; Thermo Fisher Scientific, Inc.) or anti-mouse IgG HRP-conjugated antibody (1:800, cat. no. A-11077; Invitrogen; Thermo Fisher Scientific, Inc.) at room temperature for $1 \mathrm{~h}$. Protein bands were visualized using an enhanced chemiluminescence kit (cat. no. 32132X3; Invitrogen; Thermo Fisher Scientific, Inc.). GAPDH was used as the loading control. Detection was performed using the LI-COR Odyssey Scanning Infrared Fluorescence Imaging system (LI-COR Bioscience).

Statistical analysis. All data are presented as the mean \pm SD of three experiments, and all statistical analyses were performed using GraphPad Prism 7.05 (GraphPad Software, Inc.). Differences among groups were analyzed using one-way analysis of variance (ANOVA) followed by Tukey's post hoc test. 
A

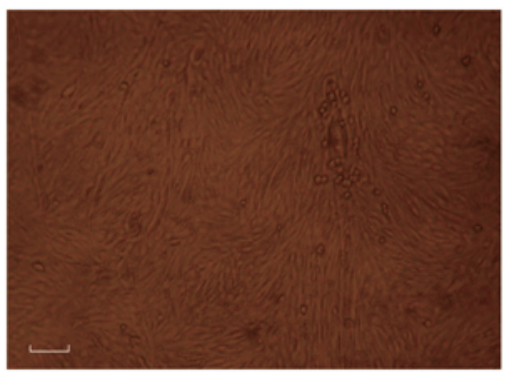

B

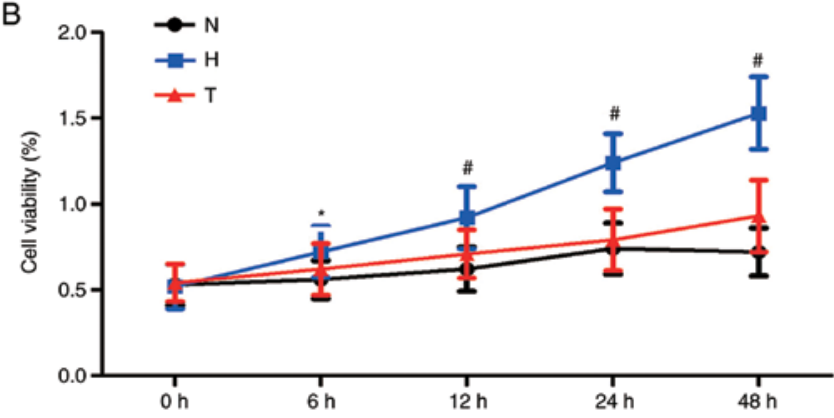

C

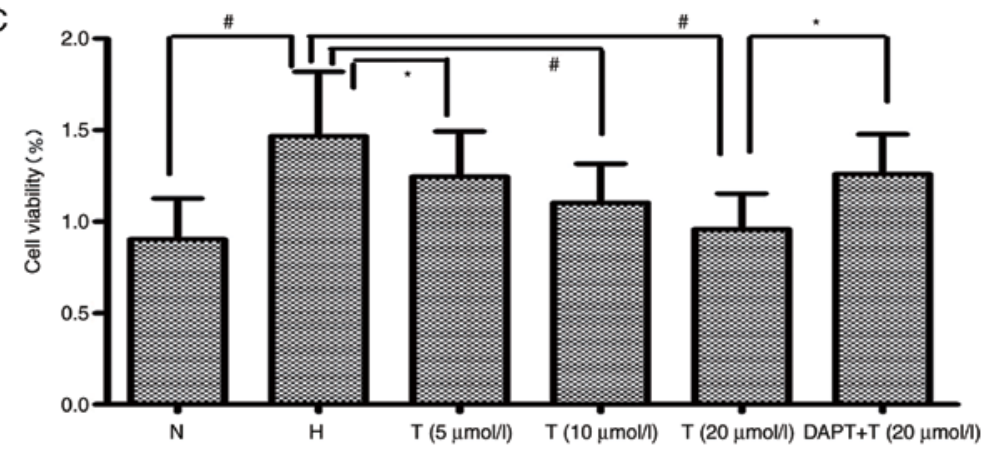

D

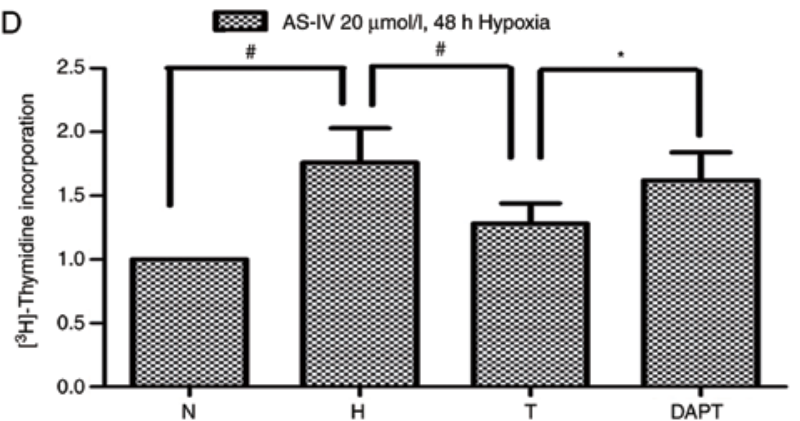

Figure 3. AS-IV inhibits hypoxia-induced PASMC proliferation. (A) Typical 'hill and valley' appearance of PASMCs. Scale bar, $10 \mu 1$. Magnification, x100. Immunofluorescence detection of $\alpha$-smooth muscle actin. The red arrow indicates skeleton protein in the cytoplasm of pulmonary vascular smooth muscle cells. Scale bar, $2.5 \mu$ l. Magnification, x400. (B) PASMCs were treated with AS-IV (20 $\mu$ mol/l) under hypoxic conditions $\left(3 \% \mathrm{O}_{2}\right)$ for $6,12,24$ or $48 \mathrm{~h}$. Cell viability was assessed by performing the MTT assay. (C) PASMCs were pretreated with DAPT ( $5 \mathrm{mmol} / \mathrm{l})$ for $1 \mathrm{~h}$, then treated with AS-IV (5-20 $\mu \mathrm{mol} / \mathrm{l})$ under hypoxic conditions for $48 \mathrm{~h}$. Cell viability was assessed by performing the MTT assay. (D) PASMCs were pretreated with DAPT $(5 \mathrm{mmol} / \mathrm{l})$ for $1 \mathrm{~h}$, then treated with AS-IV $(20 \mu \mathrm{mol} / \mathrm{l})$ under hypoxic conditions $\left(3 \% \mathrm{O}_{2}\right)$ for $48 \mathrm{~h} .{ }^{~} \mathrm{P}<0.05 ;{ }^{*} \mathrm{P}<0.01$. AS-IV, Astragaloside IV; PASMC, pulmonary artery smooth muscle cell; DAPT, N-[N-(3,5-difluorophenacetyl)-L-alanyl]-S-phenylglycinet-butyl ester; N, normoxia; $\mathrm{H}$, hypoxia; T, treatment.

$\mathrm{P}<0.05$ were considered to indicate a statistically significant difference.

\section{Results}

$A S-I V$ can alleviate hypoxia-induced pulmonary hypertension and vascular remodeling. To examine the effect of AS-IV on experimental PAH, a rat model of hypoxia-induced PAH was established. Consistent with a previous study (20), the results demonstrated that hypoxia-induced PAH model rats displayed significantly elevated mPAP levels, RV/LV+S ratios and percentage wall thickness (WT) compared with the $\mathrm{N}$ group (Fig. 2A-C). Moreover, compared with the $\mathrm{N}$ group, the $\mathrm{H}$ group displayed a notable increase in the thickness of the smooth muscle layer, as determined by H\&E staining (Fig. 2D).

Hypoxia-induced effects were significantly alleviated by treatment with AS-IV, whereas pretreatment with DAPT 
A
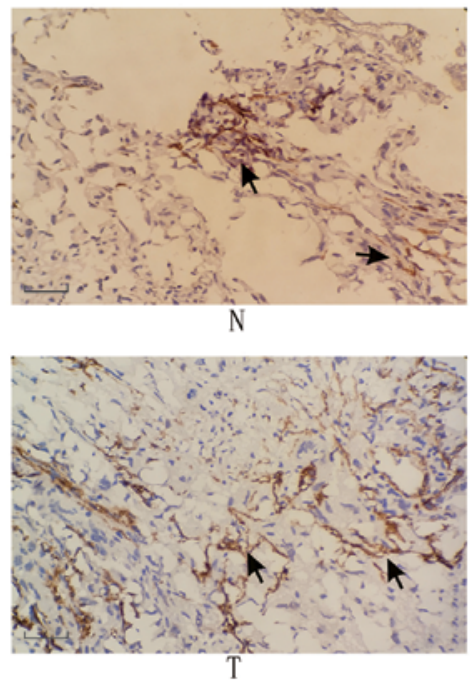

B

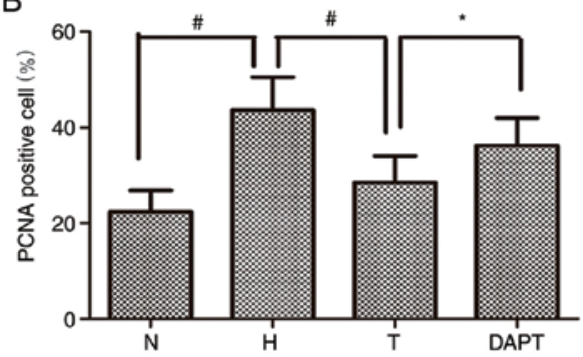

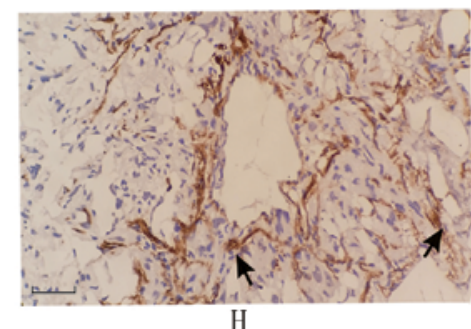

$\mathrm{H}$
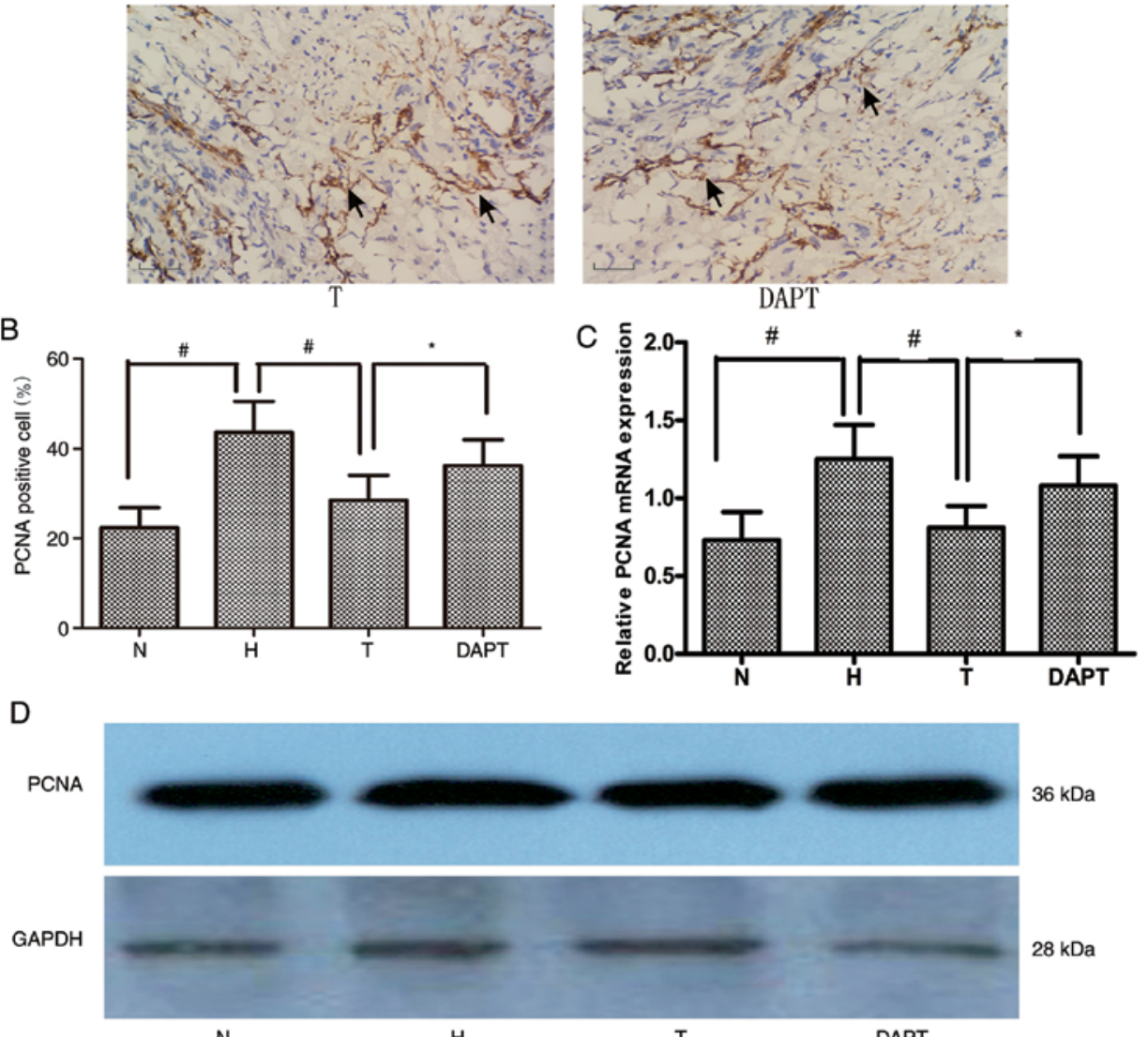

N

H

DAPT

$\mathrm{E}$

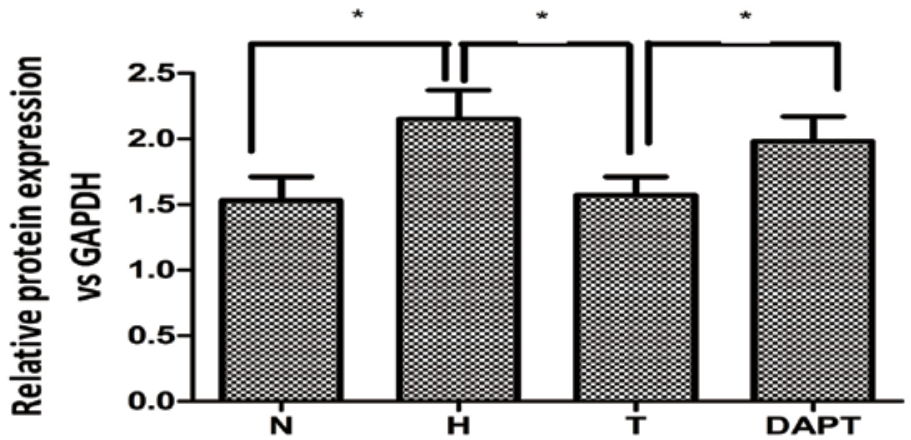

Figure 4. Effect of Astragaloside IV on PCNA expression. (A) PCNA expression was primarily detected in the pulmonary arteries (The black arrow refers to the positive expression of PCNA protein in pulmonary vascular tissue. Scale bar, $10 \mu 1$. Magnification, x100. (B) Quantification of PCNA ${ }^{+}$cells in lung sections. (C) PCNA mRNA expression in lung sections. PCNA protein expression levels in pulmonary artery smooth muscle cells were (D) determined via western blotting and (E) semi-quantified. ${ }^{*} \mathrm{P}<0.05 ;{ }^{\#} \mathrm{P}<0.01$. PCNA, proliferating cell nuclear antigen; N, normoxia; H, hypoxia; T, treatment; DAPT, $\mathrm{N}$-[N-(3,5-difluorophenacetyl)-L-alanyl]-S-phenylglycinet-butyl ester.

significantly inhibited the effects of AS-IV in alleviating hypoxia-induced responses, including alterations to mPAP, $\mathrm{RV} / \mathrm{LV}+\mathrm{S}$ ratios and the percentage WT. The results indicated that AS-IV inhibited the progression of hypoxia-induced pulmonary hypertension by pulmonary vascular remodeling via the Notch signaling pathway.
AS-IV inhibits hypoxia-induced PASMC proliferation. PASMCs displayed a typical 'hill and valley' appearance and were positive for $\alpha$-smooth muscle actin (Fig. 3A). To assess the effects of AS-IV on hypoxia-stimulated PASMCs, cell viability was measured by performing an MTT assay. The results indicated that hypoxia exposure significantly increased 
A
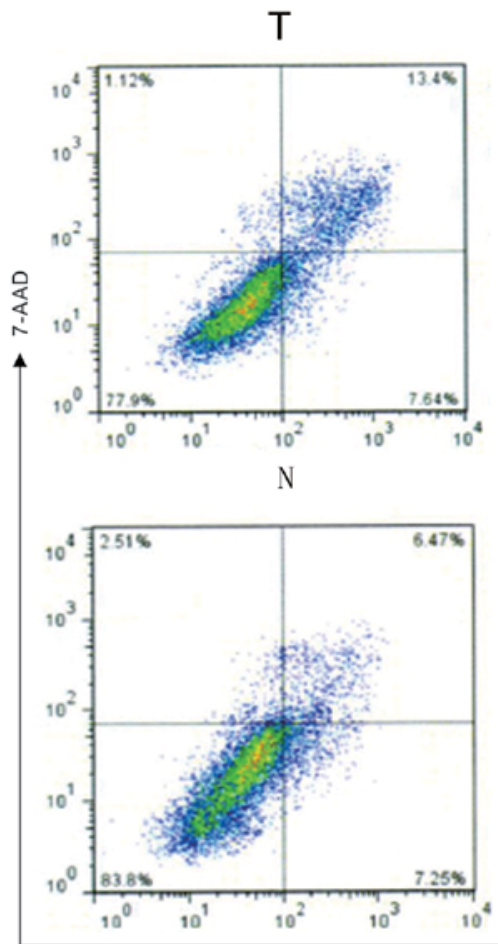

B

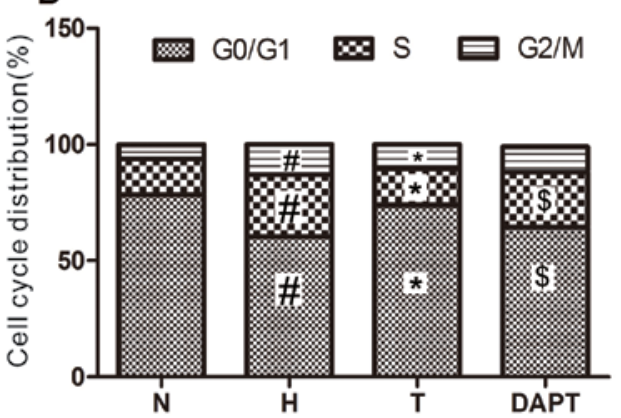

DAPT
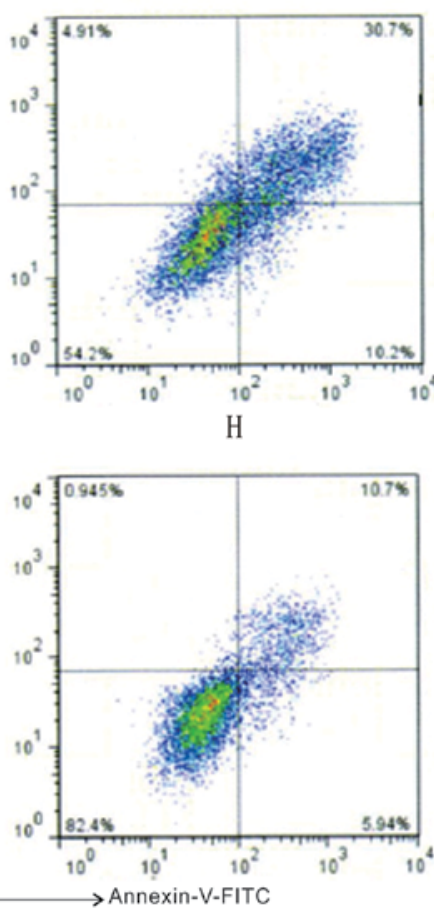

C

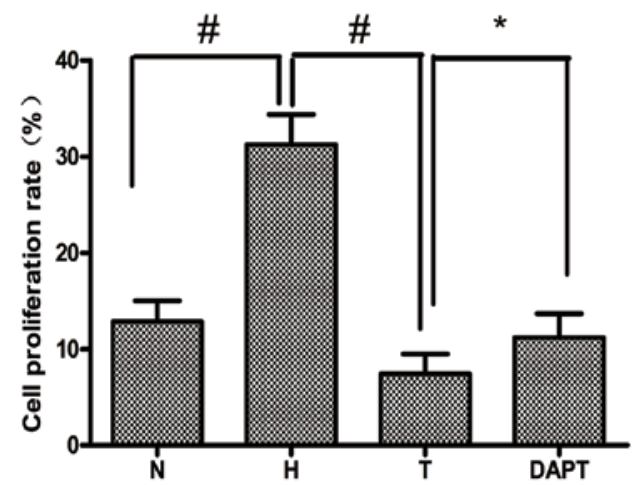

Figure 5. Effect of AS-IV on hypoxia-induced cell cycle progression. Cell cycle progression was (A) determined via flow cytometry and (B) quantified. ${ }^{*} \mathrm{P}<0.01$ vs. $\mathrm{N}$; "P<0.01 vs. $\mathrm{H}$; ${ }^{~} \mathrm{P}<0.05$ vs. T. (C) Cell proliferation index. ${ }^{*} \mathrm{P}<0.05$; ${ }^{*} \mathrm{P}<0.01$. AS-IV, Astragaloside IV; DAPT, $\mathrm{N}$-[N-(3,5-difluorophenacetyl)-L-alanyl]-S-phenylglycinet-butyl ester; 7-AAD, 7-aminoactinomycin D; N, normoxia; H, hypoxia; T, treatment.

PASMC viability compared with the $\mathrm{N}$ group. PASMC viability was increased in a dose- and time-dependent manner following treatment with AS-IV. Compared with the H group, the most significant inhibitory effects on cell viability were observed in cells treated with $20 \mu \mathrm{mol} / 1 \mathrm{AS}-\mathrm{IV}$ for $48 \mathrm{~h}$ (Fig. 3B and C). Furthermore, PASMC proliferation was significantly increased under hypoxic conditions, compared with normoxia. However, this increase in proliferation under hypoxic conditions was abrogated following treatment AS-IV with $20 \mu \mathrm{mol} / 1$ for $48 \mathrm{~h}$. DAPT pretreatment restored cell proliferation in AS-IV-treated cells (Fig. 3D).

PCNA serves important role in cell proliferation and its levels can be used as a cell proliferation index (27). Compared with the $\mathrm{N}$ group, the $\mathrm{H}$ group displayed significantly increased PCNA expression in pulmonary vascular tissue and PASMCs (Fig. 4), which was significantly reversed by treatment with AS-IV. However, DAPT pretreatment restored PCNA expression levels that were repressed by AS-IV in hypoxia-treated pulmonary vascular tissue and PASMCs. Collectively, the results suggested that hypoxia-induced PASMC proliferation was inhibited by treatment with AS-IV via activation of Notch signaling.

Effect of AS-IV on cell cycle progression. To further investigate the mechanism underlying the effects of AS-IV on hypoxia-stimulated PASMC proliferation, whether AS-IV affected cell cycle progression was examined by performing flow cytometry (Fig. 5). Compared with the $\mathrm{N}$ group, the $\mathrm{H}$ group displayed a markedly increased the cell proliferation rate and cell cycle arrest in the $S$ and $G_{2} / M$ phases. By contrast, the cell proliferation rate was inhibited by treatment with AS-IV, which notably reduced the proportion of cells entering the $S$ and $G_{2} / M$ phases compared with the $\mathrm{H}$ group. Moreover, DAPT pretreatment promoted cell cycle progression, increasing the proportion of cells entering the $\mathrm{S}$ and $\mathrm{G}_{2} / \mathrm{M}$ phases compared with the $\mathrm{T}$ group. The results suggested that AS-IV displayed an important effect on the cell cycle, inhibiting PASMC proliferation via Notch signaling. 

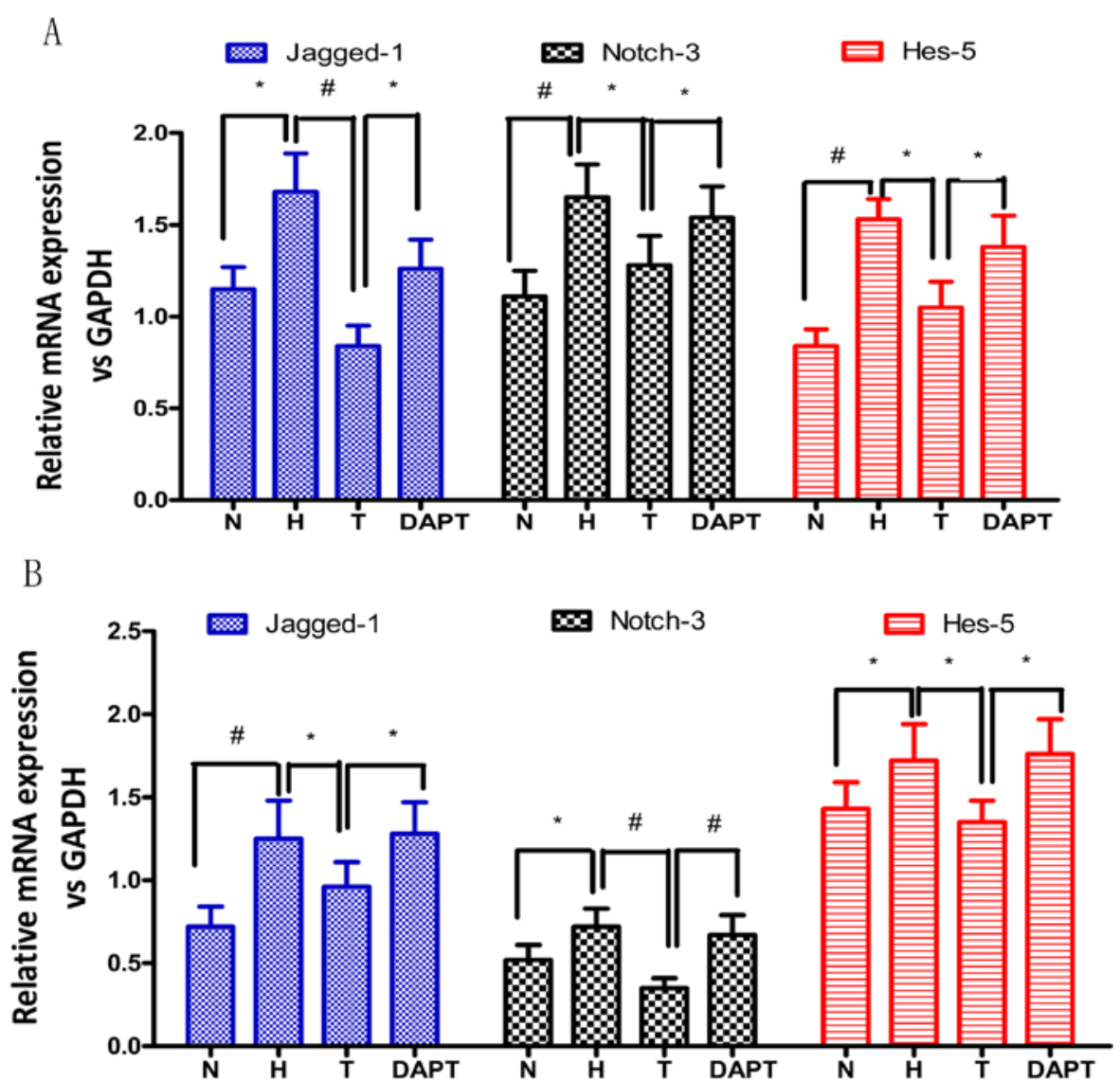

Figure 6. Effects of Astragaloside IV on Notch signaling in rat lungs and cultured PASMCs. Jagged-1, Notch-3 and Hes-5 mRNA expression levels in (A) rat lung tissue sections and (B) cultured rat PASMCs. ${ }^{*} \mathrm{P}<0.05 ;{ }^{*} \mathrm{P}<0.01$. PASMC, pulmonary artery smooth muscle cell; Hes-5, hes family bHLH transcription factor 5; N, normoxia; H, hypoxia; T, treatment; DAPT, N-[N-(3,5-difluorophenacetyl)-L-alanyl]-S-phenylglycinet-butyl ester.

AS-IV reduces Jagged-1, Notch-3 and Hes-5 expression. Subsequently, whether the Notch signaling pathway was regulated at the transcriptional level during AS-IV-mediated attenuation of hypoxic pulmonary vascular remodeling was investigated. The mRNA and protein expression levels of Jagged-1, Notch-3 and Hes-5 in rat lung tissues and PASMCs were detected via RT-qPCR and western blotting, respectively (Figs. 6-8). Jagged-1, Notch-3 and Hes-5 mRNA and protein expression levels were significantly upregulated in hypoxia-treated PAH model rats and PASMCs compared with the corresponding $\mathrm{N}$ groups. Treatment with AS-IV significantly inhibited hypoxia-induced upregulation of Jagged-1, Notch-3 and Hes-5 mRNA and protein expression levels in hypoxia-treated PAH model rats and PASMCs, whereas DAPT pretreatment significantly reversed AS-IV-mediated restoration of expression levels. The results indicated that AS-IV regulated the expression of Jagged-1, Notch-3 and Hes-5 during hypoxic pulmonary vascular remodeling in vivo and in vitro, indicating that AS-IV attenuated hypoxic pulmonary vascular remodeling via the Notch signaling pathway.

\section{Discussion}

The major finding of the present study was that AS-IV, a major biologically active compound extracted from Huangqi (Radix Astragali Mongolici), alleviated and partially reversed hypoxia-induced pulmonary vascular remodeling. Treatment with AS-IV reversed hypoxia-induced increases in the mPAP, ventricular hypertrophy, thickness of pulmonary arteriole media and cell proliferation in vivo and in vitro. Furthermore, the results indicated that the therapeutic effects of AS-IV on pulmonary vascular remodeling were associated with the Notch signaling pathway.

Pharmacological and clinical practice research has demonstrated that Astragalus displays a wide range of clinical effects, including immune regulation, cardiovascular protection, anti-inflammatory, hepatoprotective, antidiabetic, anticancer and neuroprotection $(28,29)$. As one of the primary active ingredients of Astragalus, AS-IV is regarded as the factor for quality evaluation of Astragalus in the Chinese Pharmacopeia, and has been reported to display cardioprotective (30) and anti-inflammatory effects via regulation of the NF- $\kappa \mathrm{B}$ and activator protein 1 signaling pathways (31). In the present study, AS-IV inhibited hypoxia-induced elevation of $\mathrm{mPAP}, \mathrm{RV} / \mathrm{LV}+\mathrm{S}$ ratios, pulmonary arteriole wall thickening and PCNA expression levels. Therefore, the results indicated that AS-IV attenuated hypoxia-induced pulmonary vascular remodeling.

In arterial disease, vascular smooth muscle cells are typically static and remain in the $\mathrm{G}_{0} / \mathrm{G}_{1}$ phase of the cell cycle (10). Vascular smooth muscle cell proliferation serves an important role in chronic hypoxia-induced PAH (32). Therefore, the 
A

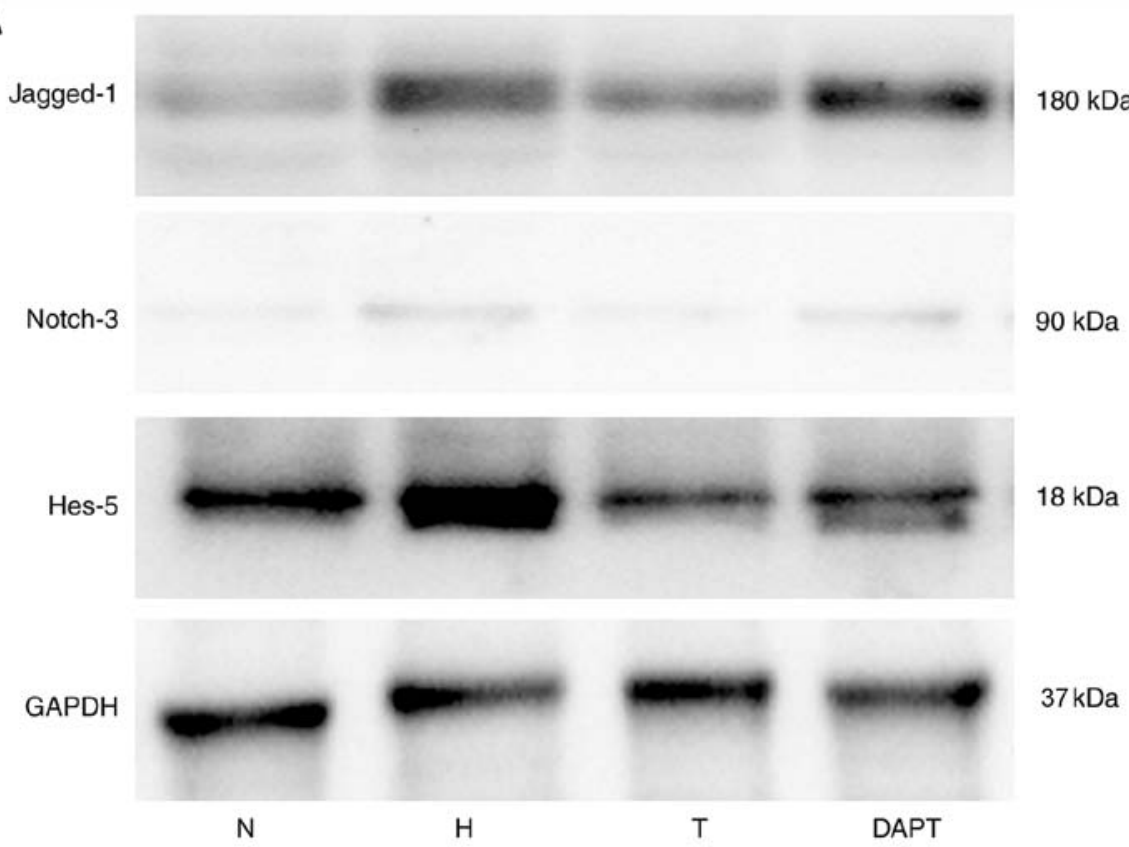

B

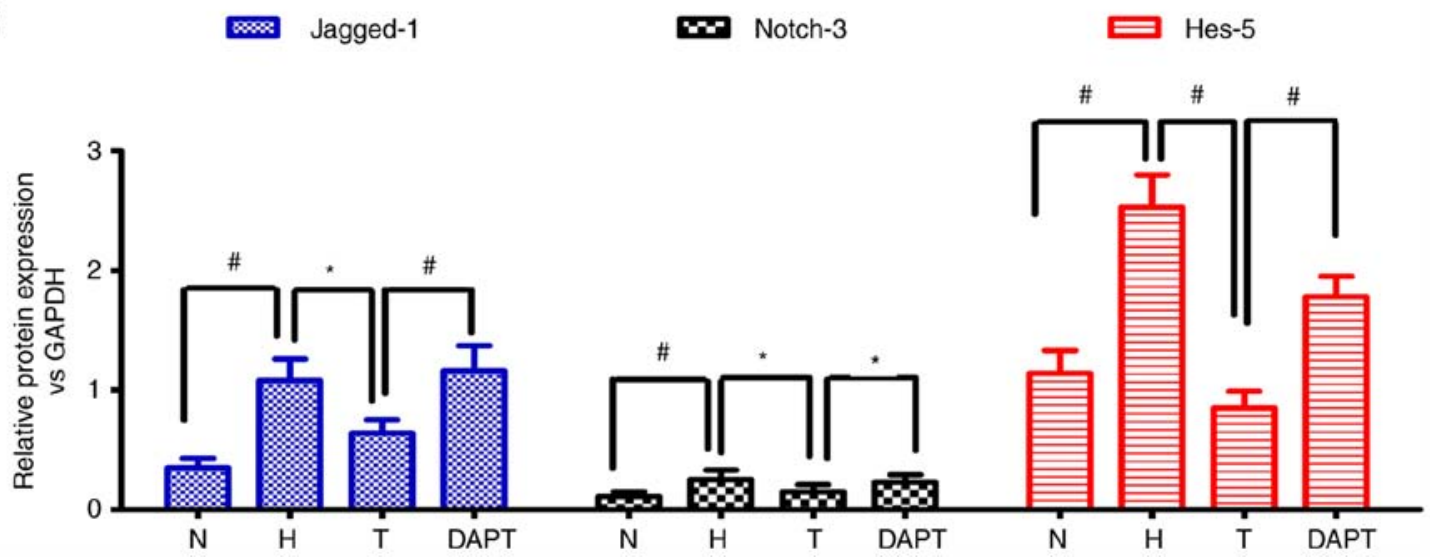

Figure 7. Effects of Astragaloside IV on Jagged-1, Notch-3 and Hes-5 protein expression levels in rat lungs. Protein expression levels were (A) determined via western blotting and (B) semi-quantified. ${ }^{*} \mathrm{P}<0.05$; ${ }^{*} \mathrm{P}<0.01$. Hes-5, hes family bHLH transcription factor 5; N, normoxia; H, hypoxia; T, treatment; DAPT, $\mathrm{N}$-[N-(3,5-difluorophenacetyl)-L-alanyl]-S-phenylglycinet-butyl ester.

present study aimed to determine whether AS-IV could exert an ameliorative effect on pulmonary vascular remodeling via inhibition of PASMC proliferation. It has been previously reported that AS-IV displays an antiproliferation effect of on angiotensin II-stimulated vascular smooth muscle cells via regulation of CDK2 activity, indicating that it displays ameliorative effects on vascular disease (33). Consistent with the aforementioned studies, the present study demonstrated that AS-IV inhibited hypoxia-induced increases in PASMC viability in a dose-dependent manner via regulating the expression of PCNA. In addition, AS-IV treatment suppressed cell cycle progression by inducing cell cycle arrest at the $\mathrm{G}_{0} / \mathrm{G}_{1}$ phase in hypoxia-treated PASMCs. Collectively, the results suggested that AS-IV inhibited cell cycle progression during PASMC proliferation, thereby reversing vascular remodeling and reducing pulmonary artery medial thickening in response to hypoxic conditions.

Several previous studies have reported that AS-IV serves an important role in cell proliferation, migration and differentiation via various signaling pathways, including p38MAPK (34),
Wnt (35), JAK2/STAT3 and ERK1/2 (36) signaling. In the present study, the results indicated that DAPT, an inhibitor of Notch signaling, significantly attenuated the effect of AS-IV treatment on pulmonary vascular remodeling and PASMC proliferation under hypoxic conditions. Moreover, the results indicated that AS-IV ameliorated hypoxia-induced pulmonary vascular remodeling and PASMC proliferation, at least in part, by regulating Notch signaling. However, further investigations are required to identify the mechanisms underlying AS-IV-mediated regulation of Jagged-1, Notch-3 and Hes-5 expression in hypoxia pulmonary vascular remodeling in vivo and in vitro.

Notch receptors and ligands expressed in pulmonary arterial vessels contribute to the regulation of endothelial cell and vascular smooth muscle cell proliferation and differentiation (19,37). Upregulation of Notch-3 receptor and ligand expression in PASMCs advances the development of pulmonary vascular remodeling in animal and clinical research (21), whereas DAPT can alleviate the development and reverse the progression of pulmonary vascular remodeling in animal 
A

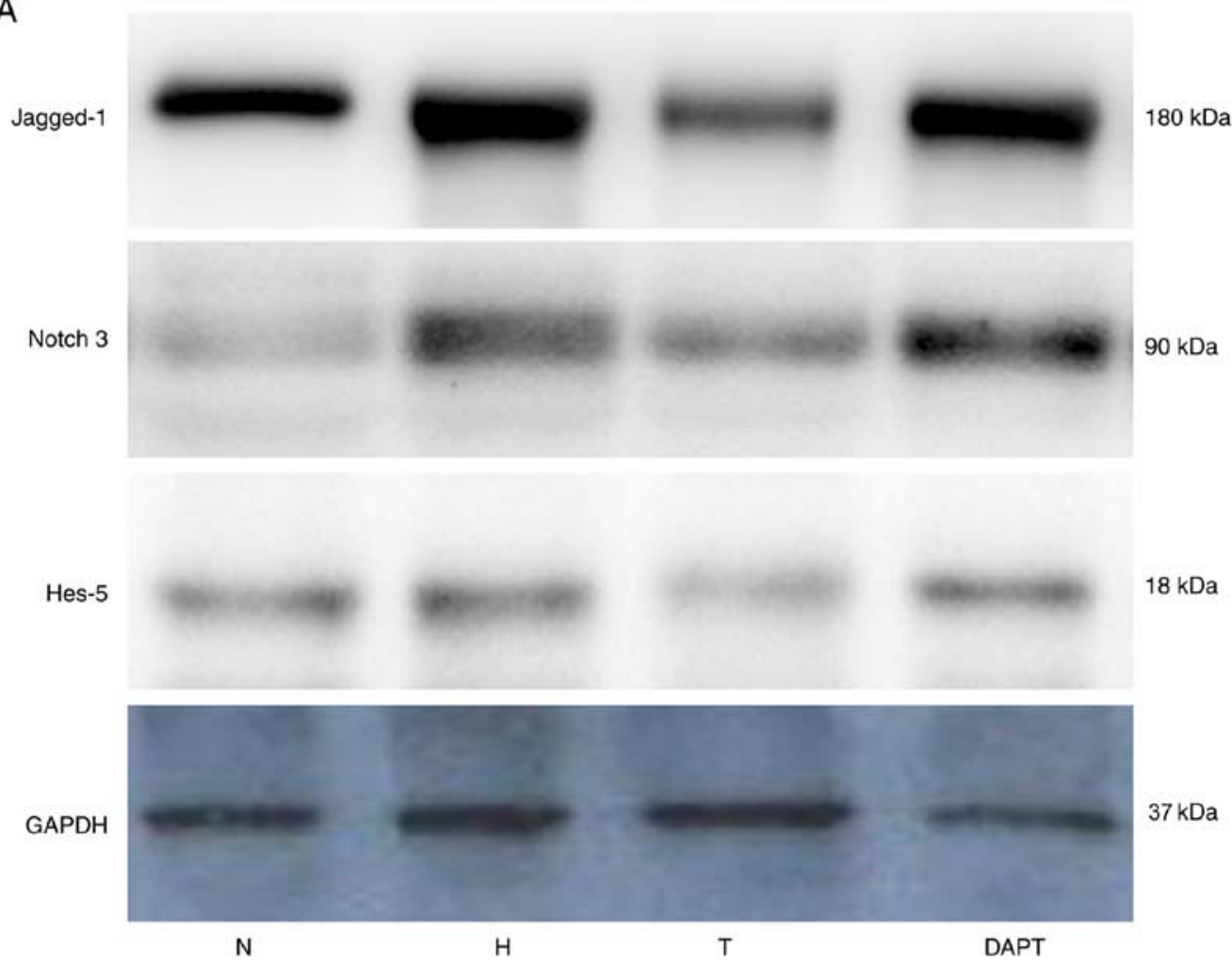

B

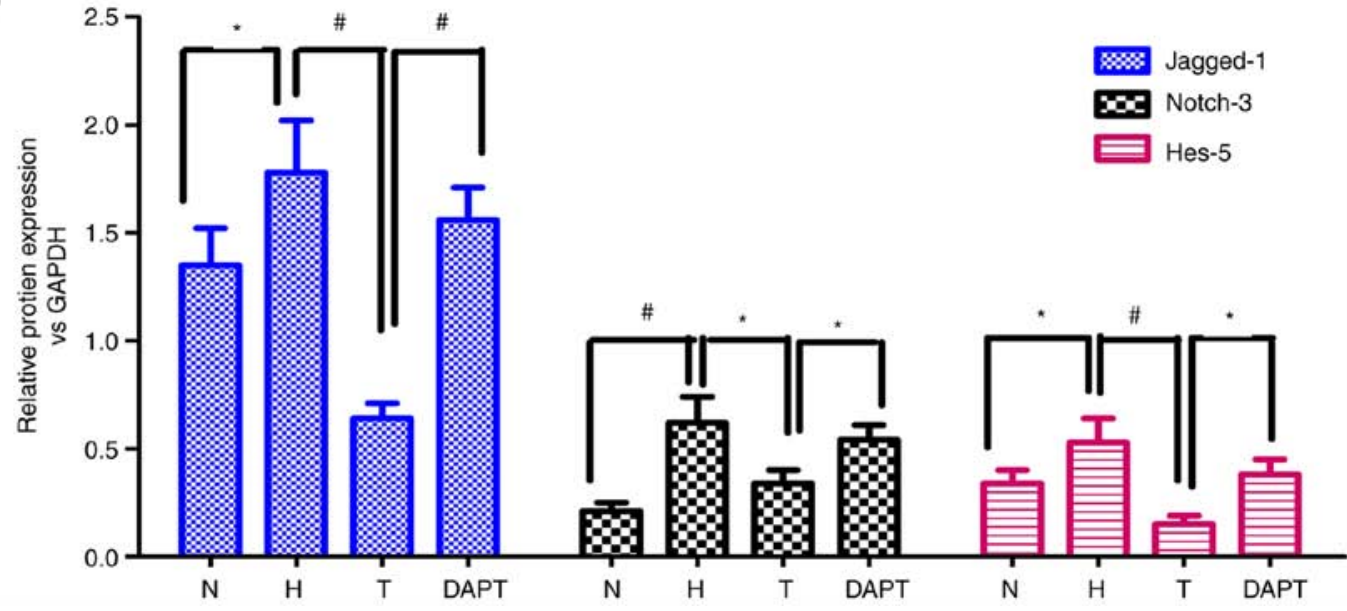

Figure 8. Effects of Astragaloside IV on Jagged-1, Notch-3 and Hes-5 protein expression levels in pulmonary artery smooth muscle cells. Protein expression levels were (A) determined via western blotting and (B) semi-quantified. ${ }^{*} \mathrm{P}<0.05 ;{ }^{*} \mathrm{P}<0.01$. Hes-5, hes family bHLH transcription factor 5; N, normoxia; $\mathrm{H}$, hypoxia; T, treatment; DAPT, N-[N-(3,5-difluorophenacetyl)-L-alanyl]-S-phenylglycinet-butyl ester.

experiments (38). The present study indicated that upregulated expression of the Jagged-1/Notch-3/Hes-5 axis was associated with the progression of hypoxia-induced pulmonary vascular remodeling in vivo and in vitro, which was consistent with the results of a previous study (39). Furthermore, the results indicated that AS-IV attenuated hypoxia-induced upregulated expression of the Jagged-1/Notch-3/Hes-5 axis in vivo and in vitro, which was consistent with a previous study that reported that DAPT can reverse the development of pulmonary vascular remodeling (40). Collectively, the aforementioned results indicated that AS-IV-mediated inhibitory effects on hypoxia-induced pulmonary vascular remodeling were associated with suppression of the Notch signaling pathway. In summary, the results of the present study suggested that AS-IV might display beneficial effects in reversing the progression of pulmonary vascular remodeling in PAH.

In conclusion, the present study indicated that regulation of the Notch signaling pathway might be important for hypoxia-induced pulmonary vascular remodeling. Moreover, the results indicated that AS-IV alleviated hypoxia-induced pulmonary vascular remodeling in vitro and in vivo. Together with the results of a previous study (41), the present study suggested that the effects of AS-IV might be mediated via downregulation of Jagged-1/Notch-3/Hes-5 expression. Therefore, the present study indicated that AS-IV might display important therapeutic functions as part of the Radix Astragali Mongolici extract for the prevention and treatment of cardiovascular disorders, such as PAH. 


\section{Acknowledgements}

Not applicable.

\section{Funding}

The present study was supported by the National Natural Science Foundation of China (grant nos. 81673858, 81704062 and 30500644), the Project of Natural Science Foundation of Hunan Province (grant no. 2020JJ8073) and the Program for National Center for Clinical Medicine for Geriatric Diseases (Ministry of Science and Technology; grant no. 2017-07-1007).

\section{Availability of data and materials}

The datasets used and/or analyzed during the current study are available from the corresponding author on reasonable request.

\section{Authors' contributions}

XF and CZ performed the experiments. GZ and JY designed the study. YY performed the statistical analyses. DW and QC analyzed and interpreted the data. QC and XF drafted the manuscript. GZ and JY critically revised the manuscript. All authors read and approved the final manuscript.

\section{Ethics approval and consent to participate}

Not applicable.

\section{Patient consent for publication}

Not applicable.

\section{Competing interests}

The authors declare that they have no competing interests.

\section{References}

1. Sakao S: Chronic obstructive pulmonary disease and the early stage of cor pulmonale: A perspective in treatment with pulmonary arterial hypertension-approved drugs. Respir Investig 57 325-329, 2019

2. Samareh Fekri M, Torabi M, Azizi Shoul S and Mirzaee M Prevalence and predictors associated with severe pulmonary hypertension in COPD. Am J Emerg Med 36: 277-280, 2018.

3. Rowan SC, Keane MP, Gaine S and McLoughlin P: Hypoxic pulmonary hypertension in chronic lung diseases: Novel vasoconstrictor pathways. Lancet Respir Med 4: 225-236, 2016.

4. Bunel V, Guyard A, Dauriat G, Danel C, Montani D, Gauvain C, Thabut G, Humbert M, Castier Y, Dorfmüller P and Mal H: Pulmonary arterial histologic lesions in patients with COPD with severe pulmonary hypertension. Chest 156: 33-44, 2019.

5. Sauler M, Fares WH and Trow TK: Standard nonspecific therapies in the management of pulmonary arterial hypertension. Clin Chest Med 34: 799-810, 2013.

6. Shimoda LA, Yun X and Sikka G: Revisiting the role of hypoxia-inducible factors in pulmonary hypertension. Curr Opin Physiol 7: 33-40, 2019.

7. Liu S, Shergis J, Chen X, Yu X, Guo X, Zhang AL, Lu C and Xue CC: Chinese herbal medicine (weijing decoction) combined with pharmacotherapy for the treatment of acute exacerbations of chronic obstructive pulmonary disease. Evid Based Complement Alternat Med 2014: 257012, 2014.
8. Ren S, Zhang H, Mu Y, Sun M and Liu P: Pharmacological effects of Astragaloside IV: A literature review. J Tradit Chin Med 33: 413-416, 2013.

9. Yuan X, Sun S, Wang S and Sun Y: Effects of astragaloside IV on IFN-gamma level and prolonged airway dysfunction in a murine model of chronic asthma. Planta Med 77: 328-333, 2011.

10. Leng B, Tang F, Lu M, Zhang Z, Wang $\mathrm{H}$ and Zhang Y: Astragaloside IV improves vascular endothelial dysfunction by inhibiting the TLR4/NF- $\mathrm{B}$ signaling pathway. Life Sci 209: 111-121, 2018.

11. Chen Z, Cai Y, Zhang W, Liu X and Liu S: Astragaloside IV inhibits platelet-derived growth factor-BB-stimulated proliferation and migration of vascular smooth muscle cells via the inhibition of p38 MAPK signaling. Exp Ther Med 8: 1253-1258, 2014.

12. Song Z, Wei D, Chen Y, Chen L, Bian Y, Shen Y, Chen J and Pan Y: Association of astragaloside IV-inhibited autophagy and mineralization in vascular smooth muscle cells with lncRNA H19 and DUSP5-mediated ERK signaling. Toxicol Appl Pharmacol 364: 45-54, 2019.

13. Spiekerkoetter E, Goncharova EA, Guignabert C, Stenmark K, Kwapiszewska G, Rabinovitch M, Voelkel N, Bogaard HJ, Graham B, Pullamsetti SS and Kuebler WM: Hot topics in the mechanisms of pulmonary arterial hypertension disease: Cancer-like pathobiology, the role of the adventitia, systemic involvement, and right ventricular failure. Pulm Circ 9: $2045894019889775,2019$.

14. Wang X, Xiao D, Ma C, Zhang L, Duan Q, Zheng X, Mao M, Zhu D and Li Q: The effect of honokiol on pulmonary artery endothelium cell autophagy mediated by cyclophilin A in hypoxic pulmonary arterial hypertension. J Pharmacol Sci 139: 158-165, 2019.

15. Wang S, Cao W, Gao S, Nie X, Zheng X, Xing Y, Chen Y, Bao H and Zhu D: TUG1 regulates pulmonary arterial smooth muscle cell proliferation in pulmonary arterial hypertension. Can J Cardiol 35: 1534-1545, 2019.

16. Borggrefe T, Lauth M, Zwijsen A, Huylebroeck D, Oswald F and Giaimo BD: The Notch intracellular domain integrates signals from Wnt, Hedgehog, TGF $\beta / B M P$ and hypoxia pathways. Biochim Biophys Acta 1863: 303-313, 2016.

17. Bigas A and Espinosa L: The multiple usages of Notch signaling in development, cell differentiation and cancer. Curr Opin Cell Biol 55: 1-7, 2018.

18. Wang Y, Dai S, Cheng X, Prado E, Yan L, Hu J, He Q, Lv Y, Lv Y and Du L: Notch3 signaling activation in smooth muscle cells promotes extrauterine growth restriction-induced pulmonary hypertension. Nutr Metab Cardiovasc Dis 29: 639-651, 2019.

19. Harrison OJ, Visan AC, Moorjani N, Modi A, Salhiyyah K, Torrens C, Ohri S and Cagampang FR: Defective NOTCH signaling drives increased vascular smooth muscle cell apoptosis and contractile differentiation in bicuspid aortic valve aortopathy: A review of the evidence and future directions. Trends Cardiovasc Med 29: 61-68, 2019.

20. Yu YR, Mao L, Piantadosi CA and Gunn MD: CCR2 deficiency, dysregulation of Notch signaling, and spontaneous pulmonary arterial hypertension. Am J Respir Cell Mol Biol 48: 647-654, 2013.

21. Song Y, Zhang Y, Jiang H, Zhu Y, Liu L, Feng W, Yang L, Wang Y and Li M: Activation of Notch3 promotes pulmonary arterial smooth muscle cells proliferation via Hes1/p27Kip1 signaling pathway. FEBS Open Bio 5: 656-660, 2015.

22. Chen X, Yao JM, Fang X, Zhang C, Yang YS, Hu CP, Chen Q and Zhong GW: Hypoxia promotes pulmonary vascular remodeling via HIF-1 $\alpha$ to regulate mitochondrial dynamics. J Geriatr Cardiol 16: 855-871, 2019.

23. Yu X, Li T, Liu X, Yu H, Hao Z, Chen Y, Zhang C, Liu Y, Li Q, Mao $\mathrm{M}$ and Zhu D: Modulation of pulmonary vascular remodeling in hypoxia: Role of 15-LOX-2/15-HETE-MAPKs pathway. Cell Physiol Biochem 35: 2079-2097, 2015.

24. Crnkovic S, Marsh LM, El Agha E, Voswinckel R, Ghanim B, Klepetko W, Stacher-Priehse E, Olschewski H, Bloch W, Bellusci S, et al: Resident cell lineages are preserved in pulmonary vascular remodeling. J Pathol 244: 485-498, 2018.

25. Yan J, Chen R, Liu P and Gu Y: Docosahexaenoic acid inhibits development of hypoxic pulmonary hypertension: In vitro and in vivo studies. Int J Cardiol 168: 4111-4116, 2013.

26. Livak KJ and Schmittgen TD: Analysis of relative gene expression data using real-time quantitative PCR and the 2(-Delta Delta C(T)) method. Methods 25: 402-408, 2001. 
27. Roels S, Tilmant K, Van Daele A, Van Marck E and Ducatelle R Proliferation, DNA ploidy, p53 overexpression and nuclear DNA fragmentation in six equine melanocytic tumours. J Vet Med A Physiol Pathol Clin Med 47: 439-48, 2000.

28. Heidebrecht F, Heidebrecht A, Schulz I, Behrens SE and Bader A: Improved semiquantitative western blot technique with increased quantification range. J Immunol Methods 345: 40-48, 2009.

29. Yang C, Mo Y, Xu E, Wen H, Wei R, Li S, Zheng J, Li W, Le B, Chen Y, et al: Astragaloside IV ameliorates motor deficits and dopaminergic neuron degeneration via inhibiting neuroinflammation and oxidative stress in a Parkinson's disease mouse model. Int Immunopharmacol 75: 105651, 2019.

30. Du J, Liu J, Zhen J, Yang ST, Zheng EL and Leng JY: Astragaloside IV protects cardiomyocytes from hypoxia-induced injury by down-regulation of IncRNA GAS5. Biomed Pharmacother 116: 109028, 2019.

31. Liu ZH, Liu HB and Wang J: Astragaloside IV protects against the pathological cardiac hypertrophy in mice. Biomed Pharmacother 97: 1468-1478, 2018.

32. Yao Y, Li H, Da X, He Z, Tang B, Li Y, Hu C, Xu C, Chen Q and Wang QK: SUMOylation of Vps34 by SUMO1 promotes phenotypic switching of vascular smooth muscle cells by activating autophagy in pulmonary arterial hypertension. Pulm Pharmacol Ther 55: 38-49, 2019.

33. Zhang DQ, Li JS, Zhang YM, Gao F and Dai RZ: Astragaloside IV inhibits Angiotensin II-stimulated proliferation of rat vascular smooth muscle cells via the regulation of CDK2 activity. Life Sci 105-109, 2018.

34. Gu L, Tao X, Xu Y, Han X, Qi Y, Xu L, Yin L and Peng J: Dioscin alleviates BDL- and DMN-induced hepatic fibrosis via Sirt1/Nrf2-mediated inhibition of p38MAPK pathway. Toxicol Appl Pharmacol 2921: 19-29, 2016.

35. Liu D, Chen L, Zhao H, Vaziri ND, Ma SC and Zhao YY: Small molecules from natural products targeting the $\mathrm{Wnt} / \beta$-catenin pathway as a therapeutic strategy. Biomed Pharmacother 117 $108990,2019$.
36. Wang $\mathrm{SG}, \mathrm{Xu} \mathrm{Y}$, Chen JD, Yang $\mathrm{CH}$ and Chen $\mathrm{XH}$ : Astragaloside IV stimulates angiogenesis and increases nitric oxide accumulation via JAK2/STAT3 and ERK1/2 pathway. Molecules 18: 12809-12819, 2013.

37. Kostina A, Semenova D, Kostina D, Uspensky V, Kostareva A and Malashicheva A: Human aortic endothelial cells have osteogenic Notch-dependent properties in co-culture with aortic smooth muscle cells. Biochem Biophys Res Commun 514: 462-468, 2019.

38. Yamamura H, Yamamura A, Ko EA, Pohl NM, Smith KA, Zeifman A, Powell FL, Thistlethwaite PA and Yuan JX: Activation of Notch signaling by short-term treatment with Jagged-1 enhances store-operated $\mathrm{Ca}(2+)$ entry in human pulmonary arterial smooth muscle cells. Am J Physiol Cell Physiol 306: C871-C878, 2014.

39. Zhang X, Chen J, Xu P and Tian X: Protective effects of Astragaloside IV against hypoxic pulmonary hypertension. Medchemcomm 9: 1715-1721, 2018.

40. Wang W, Liu J, Ma A, Miao R, Jin Y, Zhang H, Xu K, Wang C and Wang J: mTORC1 is involved in hypoxia-induced pulmonary hypertension through the activation of Notch3. J Cell Physiol 229: 2117-2125, 2014

41. Liang C, Ni GX, Shi XL, Jia L and Wang YL: Astragaloside IV regulates the HIF/VEGF/Notch signaling pathway through miRNA-210 to promote angiogenesis after ischemic stroke. Restor Neurol Neurosci 38: 271-282, 2020.

(i) $(-)$ This work is licensed under a Creative Commons Attribution-NonCommercial-NoDerivatives 4.0 International (CC BY-NC-ND 4.0) License. 